\title{
O cineclubismo de Luiz Orlando: o "desde dentro para desde fora" de um militante negro nas políticas e no mercado cinematogiráfico dos anos 1980
}

Pedro Andrade Caribét

1 Mestre e doutor em comunicação na linha de políticas de comunicação e cultura da Universidade de Brasília (UnB). Coordenador do museu digital Cinema de Terreiro. E-mail: andradecaribe@gmail.com. 


\section{RESUMO}

Na década de 1980, um militante e intelectual negro, Luiz Orlando da Silva (19452006), coordenou em Salvador uma rede de mais de cinquenta cineclubes e espalhada em territórios de história e demografia negra. O "desde dentro para desde fora" é um modo de viver e pensar o legado africano no Brasil, que encontra uma geração dos movimentos negros envolta em epistemologias de desnudamento do mito da democracia racial. Tal experiência permeia o Estado e suas políticas com foco na distribuição e na exibição, duas entraves no desenvolvimento do cinema nacional, baiano e independente.

Palavras-chave: Cinema negro. Cinema brasileiro. Diáspora. Cineclube

\section{ABSTRACT}

Luiz Orlando da Silva (1945-2006), a Black militant and intellectual, coordinated a network of more than 50 film clubs spread across territories marked by Black history and demographic composition in Salvador. From the inside to the outside is a way of living and thinking the African legacy in Brazil, which finds a generation of Black movements wrapped in epistemologies made to unveil the myth of racial democracy. Such experience permeates the State and its policies, with a focus on distribution and exhibition, two obstacles in the development of independent cinema in Brazil and Bahia.

Keywords: Black cinema. Brazilian cinema. Diaspora. Film club 


\section{INTRODUÇÃo}

Na cidade de Salvador, o Estado e suas políticas já têm uma atuação significativa no cinema e no audiovisual na virada dos anos 1970 para os anos 1980. Na definição dessa ação estão intelectuais com histórico de formulação e produção de negócios que capitalizam o reconhecimento às obras nacionais e, especificamente, baianas desde quando a geração do Cinema Novo ganhou prêmios internacionais e emergiu no século XX a consciência de que um Estadonação poderia superar a sua condição colonial e de subdesenvolvimento nas telas.

Em nível federal, a ditadura militar cria o Instituto Nacional de Cinema (INC) em 1967 e a Empresa Brasileira de Filmes Sociedade Anônima (Embrafilme) em 1969. Na cidade de Salvador a repressão não impede o funcionamento do setor de cinema da Universidade Federal da Bahia (Ufba) e dos organismos internacionais responsáveis por filmes exibidos em mostras e distribuídos para os cineclubes, a exemplo do Instituto Cultural Brasil-Alemanha (ICBA). A partir de 1974 tal cenário se expande na cidade com a criação da Fundação Cultural do Estado da Bahia (Funceb).

Todavia, o modelo hollywoodiano se aliou ao novo ordenamento segregacionista das cidades brasileiras, enquanto a TV se massifica 
nos lares com apoio dos militares. Assim, os shopping centers despontam os blockbusters, enquanto as salas populares no centro se degradam com filmes de putaria e de luta e as crescentes periferias passam a ter reduzidas as suas chances de acesso às salas exibição. Tal cenário, acompanhado por um misto de ineficiência na gestão e a ilusão liberal, levou a produção do cinema nacional, baiano e independente ao fundo do poço em 1990 com o fim do carro-chefe da política: a Embrafilme.

Ao se debruçar sobre esse tempo e cenário, o que move este pesquisador é imaginar e se perguntar como se deu a participação da população negra neste processo, visto que a cidade de Salvador é uma espécie de capital política e cultural negra do país, com a maior presença deste contingente fora da África.

O que guia tal indagação são ideias como as de Manoel Raymundo Querino (1851-1923), que, durante a vida de educador, político e pesquisador em Salvador, recontou a história a fim de demonstrar que o que concebemos como civilização no Brasil tem a contribuição chave, se não predominante, de povos africanos e seus filhos, seja na agricultura, na política, nas ciências ou nas artes (NASCIMENTO; GAMA, 2009).

Foi nessa perspectiva que, durante o desenrolar da minha tese de doutorado (CARIBÉ, 2019), encontrei memórias sobre alguém com quem convivi, mas não conheci na Faculdade de Comunicação da Ufba; ele como funcionário da videoteca, eu como estudante de jornalismo no início dos anos 2000.

Trata-se de Luiz Orlando da Silva, nascido em 1945 em Salvador, filho da doméstica e merendeira Risoleta da Silva. Ele saiu da escola antes de concluir o que conhecemos hoje como ensino médio, mas não largou os livros, revistas e jornais. Nos anos 1970, Luiz está nos passos do Grupo Nêgo, o coletivo que representa a Bahia na criação do Movimento Negro Unificado (MNU). A sua contribuição ao MNU é de um articulador, educador e curador com sugestões de discos, revistas, livros e filmes. Entretanto, sua paixão pelo cinema 
se deparou com limites ao corresponder naquele momento à afirmação do Ilê Aiyê de falar de si para si. O caminho por ele apontado é o de formar uma rede de cineclubes nos anos 1980, efetuando-o em posição subalterna às políticas do setor e à operação do poderio hollywoodiano: a conjunção entre a distribuição e a exibição.

\section{ASSENTAMENTOS}

Na cidade de Salvador, os terreiros de candomblé são mananciais de sobrevivência ao genocídio do legado africano, na leitura de Muniz Sodré (1988). O corpo, a ancestralidade, as comidas, os sons, o modo de falar, as celebrações e a integração com a natureza compõem o que Sodré defende ser uma forma cultural negra e popular que penetra no âmbito do sentido e se autoafirma no apreço à vida, comunicada por trocas comunitárias que redistribuem o segredo na leitura e no acesso ao conhecimento.

O terreiro também lastreia rodas de capoeira, samba e outras circularidades traduzidas na ocupação de ruas, esquinas, feiras e cinemas, no centro secular ou em suas invasões, baixas, vales altos

e periferias. É um manancial que os femininos de carne e osso se mesclam com o indizível para liderar - mesmo perseguidas - o desenvolvimento das casas, bem como as negociações com as instituições e intelectuais euro-ocidentais.

As filhas e filhos das comunidades de terreiro deram continuidade a esse legado, como é o caso de Deoscóredes Maximiliano dos Santos, o Mestre Didi Asipá. Ele construiu um território no qual as epistemologias nagô, jejê-fon ou congo-angola pudessem se espraiar nas galerias, bibliotecas, universidades, teatros e cinemas. Dessa forma, a Sociedade de Estudos da Cultura Negra no Brasil (Secneb) tem início em 1974 e produz, por nomes como Juana Elbein, Marco Aurélio Luz, Narcimária Luz e Muniz Sodré, pesquisas responsáveis por elaborar um escopo teórico-metodológico relacionado ao conhecimento dos terreiros, que aqui se destaca o "desde dentro para o desde fora", ou da porteira para dentro, da porteira para fora. 
Na síntese, significa viver e conceber uma experiência e linguagem africanizada e a partir dela se conectar com as estruturas euro--ocidentais e os seus mecanismos de controle e validação, conforme retoma Edileuza Penha de Souza (2008).

\section{Figura 1 - Reunião no espaço Obá Biyi}

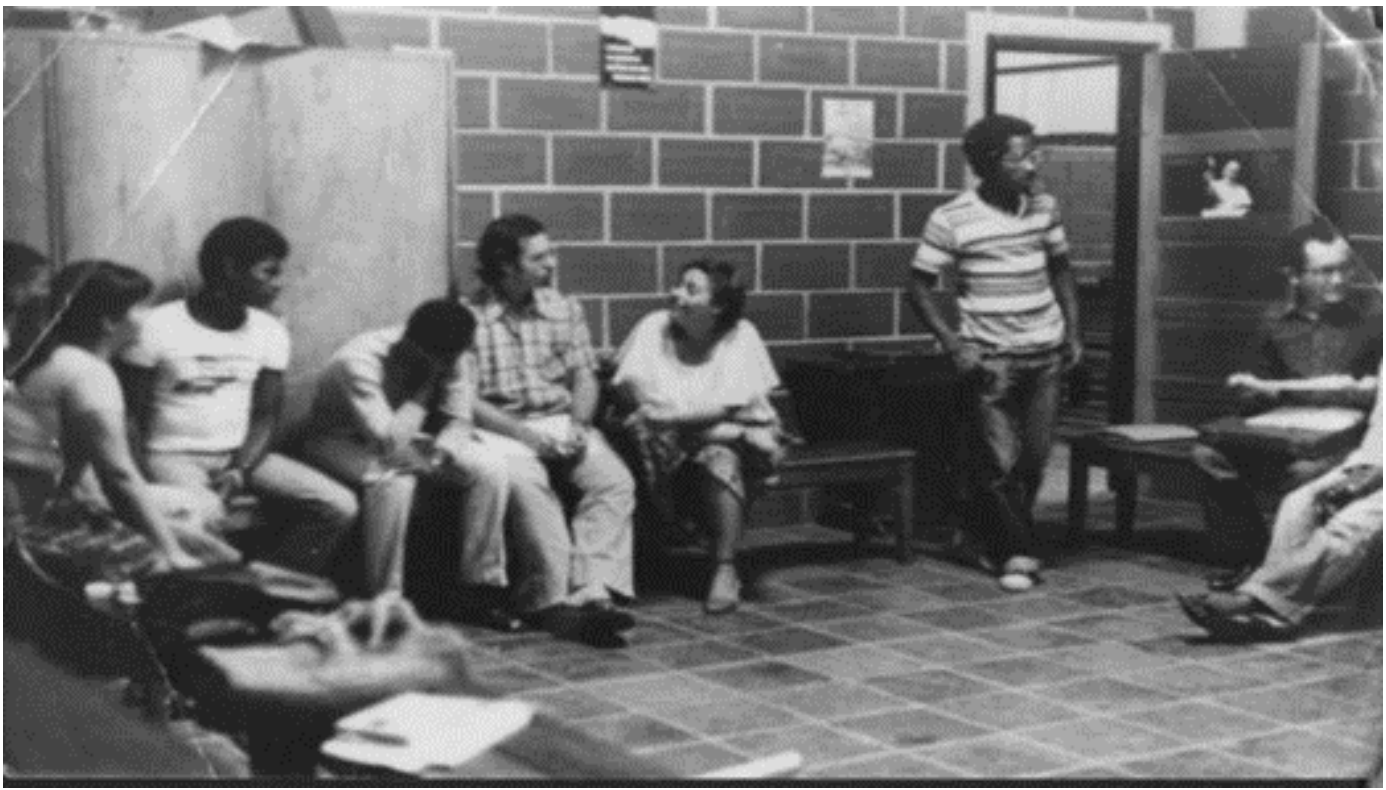

Da direita para esquerda: Muniz Sodré, Luiz Orlando (em pé), Juana Elbein, Marco Aurélio Luz e Raimundo Nascimento.

Fonte: Acervo Luiz Orlando/Arquivo Zumvi (ano desconhecido).

A sobrevivência da herança africana também segue outro caminho nos anos 1970, cujo eixo está no conceito sócio-histórico de raça. As leituras e o cotidiano de intelectuais como Jônatas Conceição, Ana Célia Silva, Lino de Almeida, Leib Carteado, Tosta Passarinho e Hamilton Vieira demonstram que aqueles que carregam aspectos fenotípicos tidos como negros ocupam espaços de subalternidade nas estruturas sociais e econômicas.

A epistemologia dessa ação é sintetizada aqui na dupla consciência, conceito extraído de Du Bois (1999) e que se define como síntese de uma teoria do reconhecimento que desnuda o véu que separa negros e não negros. Nela, os cânticos despertam a consciência que 
perpassa a autonomia comunitária, seguida por políticas e arranjos econômicos que correspondem a uma agenda normativa que abrange a educação e a participação política - mais conhecidas no Brasil contemporâneo como ações afirmativas.

O protagonista deste artigo, Luiz Orlando, fez parte dessa geração de intelectuais de identidade militante que compõe e faz uma epistemologia de quebra do contrato racial no país, na acepção de Sueli Carneiro (2005), bailando na tensão entre tal afirmação e o apelo ao universalismo que transcende a raça e questiona "noções de tipicidade e representatividade racial no juízo estético e político" (GILROY, 2012, p. 293).

Figura 2 - Luiz Orlando de boné verde na saída do llê Aiyê no Curuzu Figura

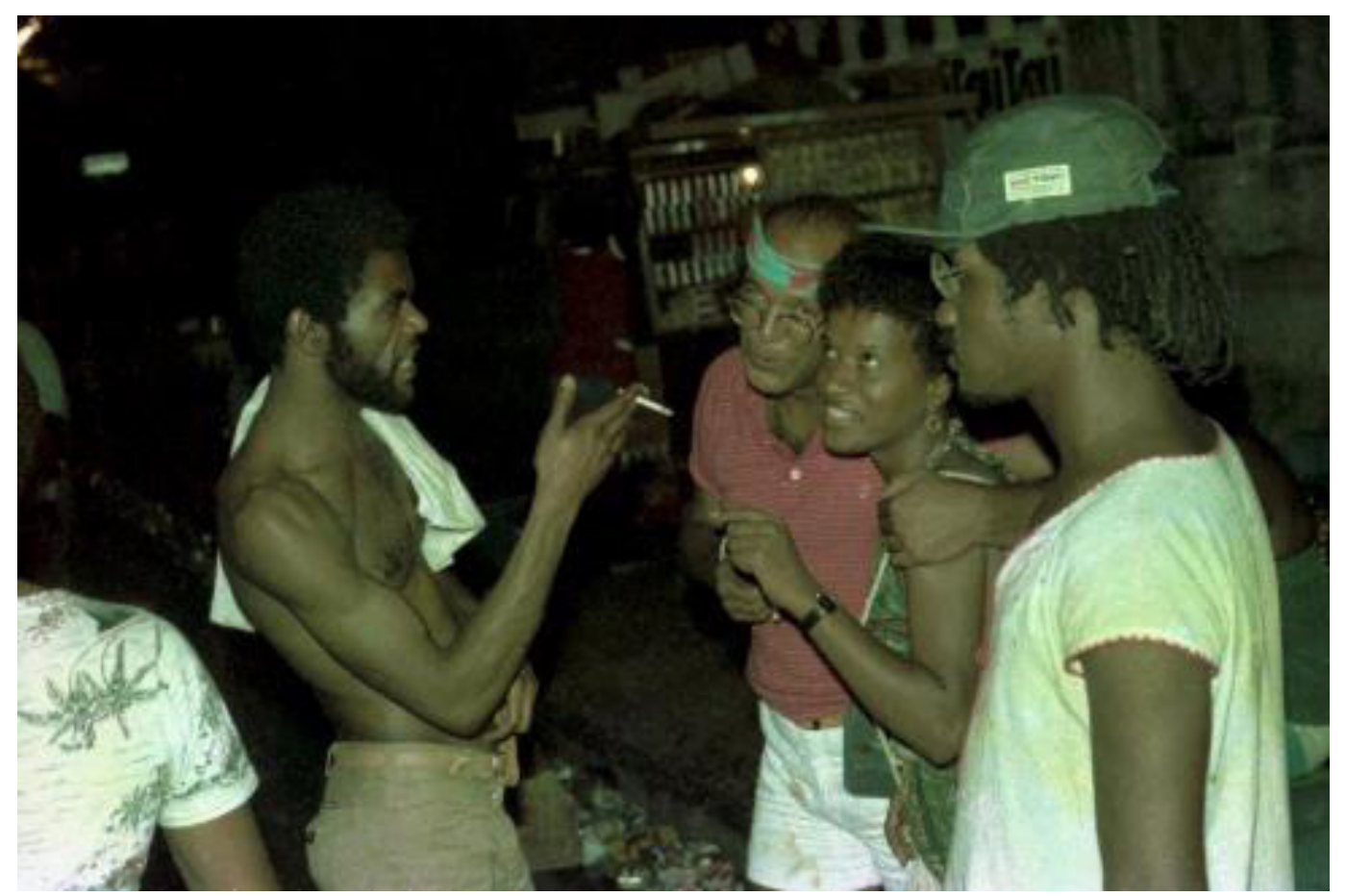

Fonte: Acervo Luiz Orlando/Arquivo Zumvi. 


\section{CINEMA DE ASSUNTO E AUTOR NEGRO EM SALVADOR}

No Brasil, diversos filmes permanecem sendo produzidos com a abordagem da herança africana na cultura e sociedade nos anos 1970. Por vezes, atores e atrizes negros, em grande medida influenciados pelo Teatro Experimental do Negro (TEN), passam a questionar dentro dos sets os roteiros, a direção e o tratamento dado aos profissionais (CARVALHO, 2005).

David Neves (1968) é um dos expoentes do Cinema Novo, de um pilar de suas concepções, o cinema de autor, e demonstra que há tensões no ar. Ele apresenta a ideia de que existiu uma ruptura na representação ao considerar as gerações anteriores do cinema nacional. Dessa vez, para ele, há um cinema negro - ou de assunto negro -, mesmo que não se identifiquem filmes dirigidos por essas pessoas, uma ausência que para ele, e para muitos até os dias dessa escrita, não configura uma questão a ser enfrentada no que é considerado um quesito basilar na modernidade do cinema nacional: o reconhecimento ao autor, negro ou negra, nas políticas de estímulo ao controle dos direitos autorais.

Salvador está integrada no acesso a obras de assunto negro em uma tríade composta pelo Clube de Cinema da Bahia, o Grupo Experimental de Cinema da Ufba, e as Jornadas ${ }^{2}$, um dos festivais mais importantes do país nesse período, marcado pela resistência à ditadura militar e a interlocução internacional, em especial com o ICBA, conforme resgata a pesquisa de Izabel Melo (2018).

O primeiro registro nesse espaço é a II Mostra Internacional do Filme Etnográfico - O Negro $(1974)^{3}$, com Alexandre Robatto: Entre o mar e o tendal (1952) e Vadiação (1954), além de O negro

2 As Jornadas mudaram de sobrenome ao longo dos anos: Baiana de Curta Metragem (1972), Nordestina de Curta Metragem (1973), Brasileira de Curta Metragem (1974-1977), Baiana de Cinema (1978-1987), Internacional de Cinema da Bahia (1988-2009).

3 Realizado com apoio do Centro de Estudos Afro-Orientais (Ceao) e da Organização das Nações Unidas (ONU), utilizando-se de acervo cedido por instituições francesas (Aliança Francesa e Museu do Homem de Paris) e norte-americanas (Serviço de Informação dos Estados Unidos e Filmoteca Shell). 
na cultura brasileira (1973), de Soares, e Integração racial (1964), de Saraceni, este último considerado por Neves (1968, p. 80) como o mais contundente: "A nivelação social do negro lhe acarreta sempre uma diminuição na coexistência com o branco, fato que as aparências brasileiras mantêm como forma de integração".

Na sessão dos estrangeiros, todos fazem menção à África. Dois deles são de diretores negros - Ritmos e imagens: $1^{\circ}$ festival mundial de arte negra do Dakar (1967), de Willian Greaves, e Grand magal a Touba (1961), de Blaise Senghor ${ }^{4}$ Também há artistas e ativistas como narradores em O congo, por Julian Bond, e em A costa dos escravos (1971), na voz de Maya Angelou ${ }^{5}$. Os demais abordam temas como Escravidão do século vinte (1971) e o apartheid na África do Sul, além dos documentários de Jean Rouch.

Já o ingresso de diretores brasileiros articulados com os discursos e a prática do movimento negro se dá na Jornada de 1977, quando é exibido o curta-metragem Alma no olho (1975). Jorge da Silva, mais conhecido como Zózimo Bulbul, roteiriza, encena, dirige e produz um ensaio poético escolhido pelo júri da Embrafilme como melhor filme $35 \mathrm{~mm}$ nessa jornada. Talvez Luiz Orlando já estivesse presente, embora o primeiro registro dele na tríade se dê em 1978, quando é apresentado 25, sobre a festa de independência de Moçambique:

[...] foi a Jornada de Cinema da Bahia, que começou a divulgar, principalmente o cinema angolano, moçambicano, e por extensão, por causa do cinema se começou a conhecer pessoas do porte de Amílcar Cabral, Agostinho Neto, né? Se interessar... Eu me lembro, não sei se foi na própria Jornada que começou a se falar, ou logo depois da Jornada, travar conhecimento com o apartheid que praticamente ninguém conhecia... E a Jornada ajudou muito a difundir a ideia de panafricanismo, luta contra os regimes de exceção, contra o colonialismo [...]. (Silva, informação verbal, 2005)

4 Sobrinho do ex-presidente e poeta Leopoldo Senghor. Grand magal a Touba é um documentário sobre a peregrinação da Irmandade Mouride. Foi premiado no Festival de Berlim de 1962.

5 A costa dos escravos é um documentário sobre os Ashanti em Gana e os lorubás na Nigéria 
Ele entra na tríade meio que por acaso, pois achavam que era estudante. Inicia como bilheteiro, passa a cuidar do transporte e armazenamento dos filmes, se familiariza com os distribuidores e aprende a projetar com suavidade, sem colocar em risco as películas. O cabelo black e a fala mansa sempre com referências e análises. Luiz já era das cercanias do bairro do Engenho Velho de Brotas, mas transitava na vida de uma classe média branca no centro, permeado por livrarias, teatros, bibliotecas, grupos clandestinos no combate à ditadura e a turma contracultura, a qual os pretos como Mario Gusmão eram gatos pingados (BACELAR, 2006).

Nas discussões da linha de frente da Jornada, a figura do diretor ainda predominava. Desse modo, um negro como Agnaldo Siri Azevedo consegue amplificar a sua voz após realizar curtas como Boca do inferno (1974) e Carbonado ou Xique-xique de Andaraí: a cidade fantasma (1976). Ele integra um grupo que realiza filmes em $16 \mathrm{~mm}$, sob tensões com superoitistas, críticas à proximidade das Jornadas com produtores e intelectuais do Sudeste e as fragilidades das políticas estaduais, analisados por Melo (2018) como reprodutoras de um mesmo habitus, sem promover rupturas no campo, mas sim disputas internas por capital simbólico.

Já Luiz Orlando tem acesso a equipamentos que o permitem difundir nas ruas e se aproximar do Conselho Nacional de Cineclubes (CNC), responsável pela Dinafilmes, uma distribuidora criada em 1976 com a pretensão de formar um mercado paralelo. É por aí que Luiz se aproxima dos encontros nacionais e das ideias de Jean-Claude Bernardet, defensor do corpo dos cineastas nos circuitos e crítico da figura do programador. Para Bernardet (1980), deveria haver uma organicidade entre filmes e público, mas deixa como observação se tratar de uma perspectiva teórica porque os cineclubistas não têm penetração popular. 


\section{FUNDAÇÃo CULTURAL: COMPARTILHAR A ARTE DE PROJETAR}

A possibilidade de Luiz ampliar o alcance do cineclubismo se dá em 1981, ao ser contratado pela Funceb para o Programa de Ações Socioeducativas e Culturais para as Populações Carentes Urbanas (Prodasec) com recursos do Ministério da Educação e Cultura (MEC). Os ares da reabertura chegam nos cursos de teatro, dança, fotografia e cinema com a estrutura de uma Kombi, quatro projetores e filmes nos arredores do nordeste de Amaralina, Liberdade, Alagados, Suburbana e Cabula, em Salvador.

No começo Luiz vê com cautela: "Confesso que quando me chamaram para trabalhar no Prodasec fiquei meio balançado porque a gente sempre fica desconfiado das coisas que vêm do lado oficial" (CINECLUBE..., 1982, p. 20). Ainda assim ele topou, mas com uma contraproposta para expandir o que tinha em mãos: "Ele [Luiz] foi muito inteligente nesse aspecto. Era um projeto público para projetar filmes nos bairros e, ao invés de projetar, ele criou oficinas de projeção", comenta Velame (informação verbal, 2019), então morador do Beiru.

O projetor escolhido é nacional, o Iec de $16 \mathrm{~mm}$, mais barato, mais leve para carregar, mais fácil de aprender a manejar e mais fácil de obter cópias. A tática dá certo e o segundo passo é escolher o local. Aí vale de tudo: praça, escola, bar, associação, rua, igreja, terreno baldio.... Bastava um lençol branco, um projetor e a caixa de som. Desloca-se, assim, o eixo do debate nos círculos da cinefilia:

Está havendo a desmistificação do cinema na periferia. Está acabando aquele mito de que um filme só pode ser exibido neste ou naquele projetor, num cinema moderno com excelente acústica, de preferência com ar-condicionado. Nosso equipamento básico é o projetor nacional, por sinal, que nem é grande coisa. Não usamos tela metálica, não usamos mesa de projeção, nem nada. Utilizamos uma parede branca, um lençol, qualquer coisa. (CINECLUBE..., 1982, p. 21) 
No findar do segundo ano de atuação, o relatório do Prodasec indica que esses locais geraram 474 projeções para um público de 83.452, um número que, somado aos cinquenta pontos de exibição registrados, é considerável, pois as salas de cinema estavam em declínio no país ${ }^{6}$, principalmente aquelas propensas às cinematografias de círculos como as Jornadas e as salas de arte.

\section{OS FEIOS, SUJOS E MALVADOS NO CONSELHO NACIONAL DE CINECLUBES}

O crescimento do cineclubismo desperta uma organização para ampliar a autonomia e o relacionamento com instituições públicas e privadas. Dessa forma, a Federação Baiana de Cineclubes (FBC) é criada em 1984 e, nas três gestões, até 1989, Luiz Orlando foi o presidente. ${ }^{7}$

A FBC também credencia participação no CNC. Nos anos 1980 há um desprestígio do cineclubismo, quando as lógicas de mercado passam a comungar com as organizações e intelectuais do cinema nacional. Foi então que o discurso de chegar até o povo e a partir dele realizar um projeto de desenvolvimento nacional se deparou com uma delegação baiana na XVII Jornada de Cineclubes de Piracicaba (1982).

Diogo Gomes também é baiano, mas vivia há tempos em São Paulo, onde coordenava a Dinafilmes. Ele vira amigo de Orlando e recorda as reações:

Muita gente começou a dizer que ele não teorizava. Teve um pau muito pesado, de um lado os de periferia, versus o partidão. Chegou num nível que quase saiu uma chapa de oposição, porque queriam que ele fosse presidente, e ele nunca aceitou ser da direção nacional. Foi provocado pelo então presidente do conselho [Felipe Macedo], e falou: "Este filho da puta me paga, vou vir

6 Havia, em 1971, 2.174 salas, enquanto em 1989 havia 1.520 (OCA, 2020).

7 Em 30 de junho de 1988 é aprovado o Projeto de Lei 57/1988 da Câmara Municipal que considera a FBC entidade de utilidade pública. No mesmo ano o Ministério da Cultura (MinC) a inscreve no Cadastro Nacional de Pessoas Jurídicas, o que a habilita a receber patrocínio e doação com base na Lei 7.505/1986, mais conhecida como Lei Sarney. 
com um ônibus". Um ano seguinte em Petrópolis a Bahia chegou com um ônibus apinhado. Nessa Jornada é a primeira vez que ele se colocou como liderança, chegou com um grupo, na mesma época que Olodum grava seu LP. Ele chegou com o pessoal acordando todo mundo. Os encontros eram festivos, mas a delegação chegou atrasada, e era um convento, e acordou todo mundo, tudo colorido, no outro dia apareceu um troféu Feios, Sujos e Malvados. Tinha uma dubiedade muito grande, a maioria era negra. Pegou mal pra caramba. (Diogo Gomes, informação verbal, 2017)

Feios sujos e malvados (1976), de Scola, se passa numa favela de Roma, onde uma família de dezesseis pessoas se mantém unida em um barraco, em tom animalesco, misturada com sujeira, sexo, estupros, roubos, agressões e toda a sorte de transgressão. É possível que muitos dos atingidos pela analogia não tivessem assistido ao filme, mas não era necessário, pois o recado estava dado. Gente negra ali só da Bahia, fora algumas exceções, como o paulista João Batista Félix, que recorda: “Antes de Luiz o movimento era europeu" (informação verbal, 2017). Ele o conhece timidamente no encontro do MNU de 1982, e ficam grandes amigos ao discutir sobre o ganês Kwame Nkrumah, o angolano Agostinho Neto, o martinicano Frantz Fanon, Malcolm-X, a saga Raízes de Alex Haley, Clóvis Moura e por aí vai.

Quando começa a frequentar os encontros do CNC, Batista traz a experiência de fomentar sessões em escolas de samba até se deparar com uma rede inédita no país, que o fez acreditar mais nesse caminho: "Ele [Luiz] tinha trabalho de base, na periferia, no Olodum, tinha contato com todos os blocos afros. Ele ia até lá. Quando ia à Bahia diziam: "Ele é o homem do cinema pra gente"” (João Batista Félix, informação verbal, 2017). Tanto era reconhecido que conseguiu envolver gente como o ogã e professor Jaime Sodré, escolhido vice-presidente do CNC (1984-1986) na chapa Feios, Sujos e Malvados, presidida por Diogo Gomes. 
Figura 3 - XVII Jornada Nacional de Cineclubes de Piraciaba, 1982

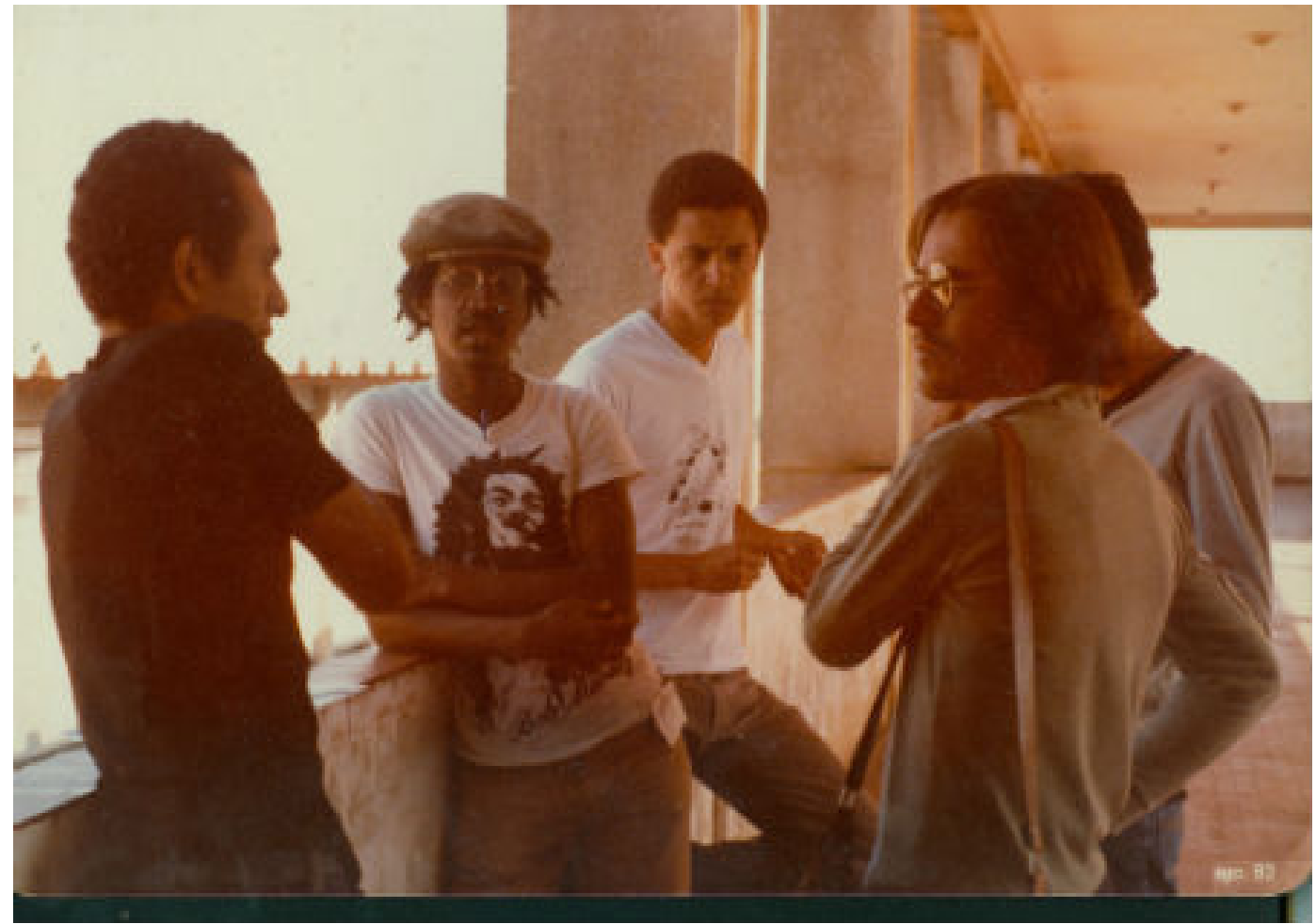

Fonte: Acervo Luiz Orlando/Arquivo Zumvi (1982).

\section{OS INVASORES DAS JORNADAS BAIANAS}

Jánas Jornadas deCinemana Bahia, Luiznãoassume postos decoordenação, como lembra Raimundo Nascimento, que foi estagiário na tríade: "Ele não era uma pessoa como a maior parte dos negros, ainda mais mexendo com cinema, mas não era do núcleo duro da definição das questões da Jornada em si" (informação verbal, 2017). A falta de legitimidade também se ramifica nas discussões e na gestão sobre as políticas de exibição envolvendo equipamentos, como o Cine Guarany, o Espaço Cultural Alagados, e o Cine Teatro Lauro de Freitas. Na reportagem "Espaços Alternativos", o presidente da empresa responsável pela gestão em Lauro de Freitas e Alagados diz não ter sido procurado pelos cineclubistas. Já para o diretor José Humberto: 
O cineclube tornou um caminho faccioso no Brasil, puramente ideológico. $\mathrm{O}$ cineclube não tem nenhum interesse pela linguagem do cinema, e cinema continua sendo cinema. Não tem um cineclubista escrevendo sobre filme. (JORNAL DA XV JORNADA BAIANA DE CINEMA, 1986, p. 11)

O marco foi levar membros da FBC para compor o júri popular em 1987 e 1988, quando o vencedor convergiu com o júri oficial na categoria vídeo de média metragem, como bem lembra Jeane Costa, mais conhecida como Déa:

Até hoje me emociono. O filme que ganhou foi Terra para Rose. Lembro que o grande debate, depois da gente, não era muito profundo de cinema, mas o que faz você gostar de um filme é a emoção. Se eles acreditavam que a gente não entendia, como conseguiu eleger o mesmo? Eles foram levados pelo mesmo sentimento... Luiz nunca teve um espaço como poderia ter tido dentro desse grupo da universidade, e isso pra ele foi uma realização muito importante. (Jeane Costa, informação verbal, 2017)

Na Jornada de 1988, o horizonte da população negra em dirigir os seus próprios filmes volta a ecoar com o documentário Abolição (1988), de Zózimo Bulbul, neste que era a única cópia disponível e ainda por cima em 35mm. O segundo diretor negro identificado nesta programação é Ras Adauto (Adauto de Souza Santos) que, ao lado de Vik Birkbeck, realiza pela pioneira Enúgbarijo Comunicações A marcha e a farsa (1988), um registro em vídeo da caminhada do movimento negro no Rio de Janeiro, coagida por forças policiais no dia 11 de maio de 1988.

Muitos outros vídeos e películas de 35mm foram exibidas nessa Jornada, dentre eles produções latino-americanas com ênfase nos retratos dos mexicanos nos Estados Unidos da América (EUA) e outros tantos relacionados à população negra, abordando: João Cândido, meninos de rua, blocos afro, ${ }^{8}$ o surgimento do MNU, ${ }^{9}$

8 Karnaval ijexá (1988), de Luiz Ferro. Blocos afro com depoimento de Gilberto Gil

9 Raça na praça (1987), de Pereira e Gal. Manifestação na Praça Ramos de Azevedo que deu 
empregadas domésticas, ${ }^{10}$ a exploração dos haitianos nas plantações de cana de açúcar, ${ }^{11}$ a mulher negra em Salvador, ${ }^{12}$ o culto à Escrava Anastácia, ${ }^{13}$ a pequena África no Rio de Janeiro, ${ }^{14} \mathrm{a}$ africanização religiosa ${ }^{15} \mathrm{e}$ alguns com sinopses que ultrapassam os limites do diálogo da representação do outro sobre si. ${ }^{16}$

É difícil detalhar a presença de profissionais negros fora da direção. É certo, porém, que Raça Negra foi premiado com o Tatu de Ouro na categoria melhor vídeo média-metragem, com a presença de Luiz Orlando na assessoria e direção de Nilson Araújo. Na abertura são mostradas fotografias nas palafitas de Alagados, seguidas por uma denúncia do petroleiro Luiz Alberto e a música Raça Negra, composta por Gibi e Walmir e gravada no primeiro álbum do Olodum. São marcas umbilicais de Luiz na obra, que contém os depoimentos de seu colega de infância, Zulu Araújo, o amigo Mestre Cobrinha, no apoio da Funceb, ${ }^{17}$ além de uma turma de cineclubistas na equipe. ${ }^{18}$ Nos anos seguintes, quando o vídeo monopoliza as exibições alternativas, essa obra seria uma das

origem ao MNU em São Paulo (1978).

10 Duas vezes mulher (1988), de Eunice Gutman. Entrevistas com migrantes da zona rural, empregadas domésticas e residentes na favela do Vidigal-RJ

11 Açúcar negro (1987), de Michel Regnier. Documentário sobre a República Dominicana, onde os haitianos vivem muitas vezes em trabalho escravo.

12 Eu sou neguinha? (1988), de Mônica Simões.

13 Anastácia: escrava e santa (1987), de Joatan Vilella Berbel. Culto e reivindicação para canonização da Escrava Anastácia.

14 Okê jumbeba - a pequena África no Rio de Janeiro (1985), de Roberto Moura. No pós-abolição ocorrem a remoção da população negra do centro do Rio de Janeiro, o crescimento das favelas e a revolta urbana de 1904.

15 Dia de erê (1978), em São Paulo. São Cosme e Damião em rituais de Umbanda e na Igreja Católica.

16 Isabel e seus negrinhos (1988), de Cláudio Ferrario. Um repórter travestido de Princesa Isabel liberta os repórteres escravos, Nega Maluca e Piolho, para saberem o que as pessoas achavam da abolição; Senzala no asfalto (1988), de Ferreira. Formula a hipótese de que a luta de negros e brancos é uma só: a luta contra um sistema que oprime e domina o homem.

17 A produção é do Centro de Produção Cultura e Educativa da UNB e da produtora Século XX.

18 A equipe tinha Umbelino Brasil (produção executiva), Diogo Gomes (roteiro e produção executiva), João Batista Félix (colaboração), Tatiana Lima (entrevista) e Antonio Velame (assistente de produção). 
mais utilizadas no catálogo de Luiz, um sinal da sua disposição em transformar as redes de distribuição e exibição cineclubistas em produtoras de conteúdo.

Figura 4 - Luiz Orlando, no canto inferior esquerdo, no auditório ICBA durante a Jornada de 1982

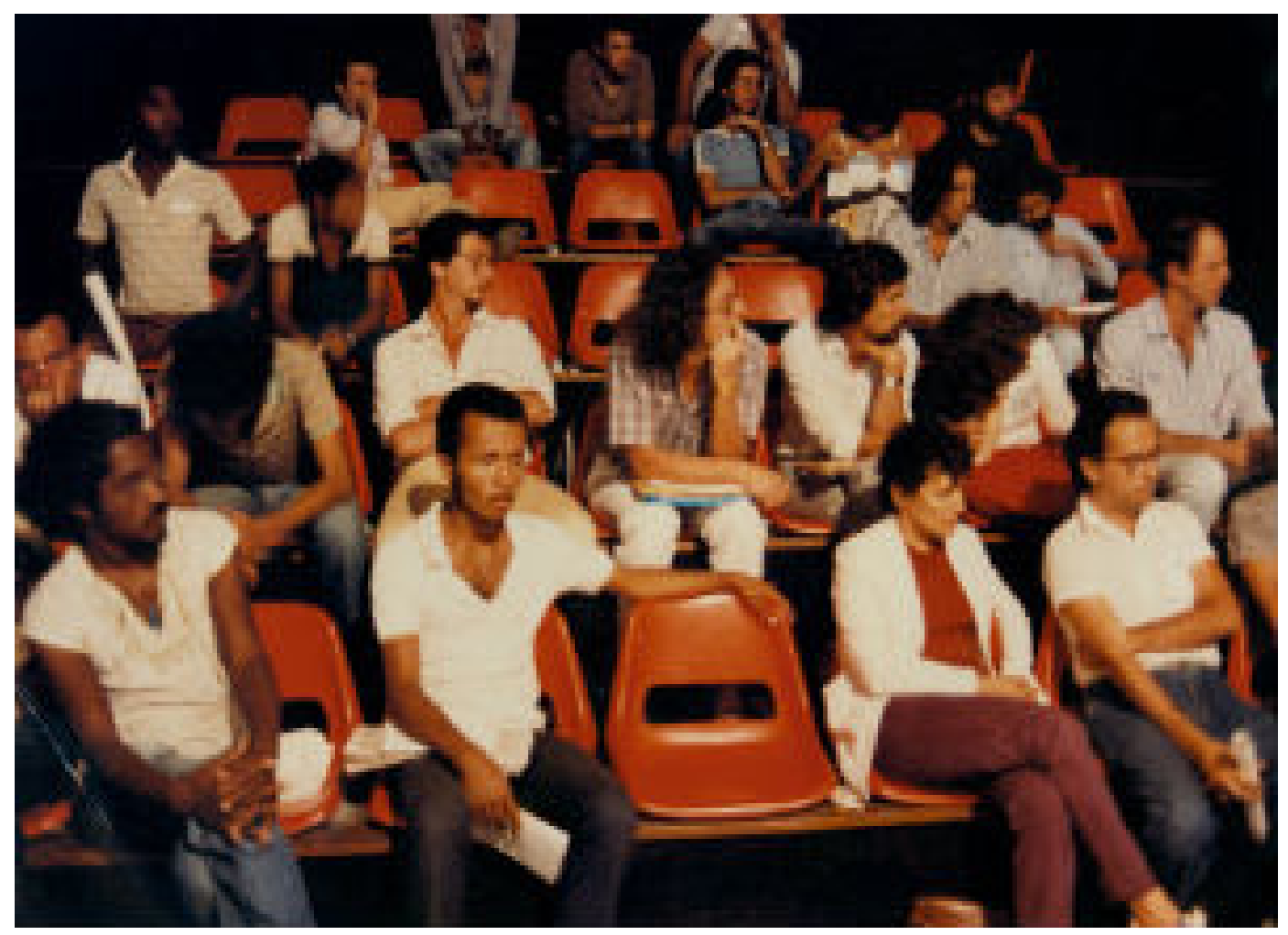

Fonte: Acervo Luiz Orlando/Arquivo Zumví (1982)

\section{VIVER E CONCEBER FILMES}

Umfilme quepudesse tocara plateia com risos ou choros já era motivo de vitória equantomais gentemelhor - eraocasode sucessos comerciais como OstrapaIhöeseXica daSilva(1976), de Carlos Diegues. Sóquea maioriaépouco conhecida até os dias desta escrita, basicamente curtas-metragens e documentários. O domínio nacional tinha como origem doze fontes de distribuição, ${ }^{19}$ sendo as $\ldots \ldots . . .0$

19 Embrafilme, Dinafilmes, Filmoteca da Bahia (Ufba), Jornadas de Cinema, ICBA (alemães), Setro 16mm, Aliança Francesa, Centro de Informações da ONU, Filmoteca do Consulado 
principais a Dinafilmes, a Jornada e a Filmoteca da Bahia, localizadas na tríade e sob os cuidados de Luiz, que se fortaleceu ao se tornar funcionário efetivo da Ufba na primeira metade dos anos 1980. Os curtas só ganhavam força quando faltava dinheiro para o aluguel, ${ }^{20}$ além da demanda do público, que passa a utilizá-los como meio de debates:

Só entrou discussão mesmo quando entrou o curta-metragem, principalmente quando a Fundação encerrou o projeto. Não tinha dinheiro, não tinha mais condições. O que é que começou a se fazer? Vamos discutir, trabalhar nossa realidade com o curta-metragem. As pessoas pediam mesmo. O negócio espalhou de tal jeito que o pessoal fazia cobrança, nós tínhamos que correr atrás: "Eu quero um filme que trate de menino de rua", que não tinha tanto como tem agora. "Filme que trate da situação do negro no Brasil". Filme de gênero, temático. Só que tinha um problema muito sério, porque as pessoas pegavam o filme como mero pretexto pra discutir sua situação, e não o que o filme tava exibindo. (Silva, informação verbal, 2004)

Mas o que era a experiência vivida na recepção dos filmes nesses territórios?

No Pelourinho, passado, presente e futuro se cruzam em três cineclubes: do Maciel, Olodum e Policarpo Quaresma. O tom de denúncia das condições de vida está em Comunidade Maciel: há uma gota de sangue em cada poema (1974), de Tuna Espinheira, mas há uma perspectiva de fugir de um juízo final neste documentário baiano e resgatar o legado de grandiosidade que corre nos velhos sobrados em Tendas dos milagres (1977), de Nelson Pereira dos Santos, inspirado em Manoel Querino, um intelectual que

do Canadá (filmes McLaren), filmes soviéticos e a Polifilmes. Conferir: Roteiro de apresentação sobre Cineclubes Populares, Acervo Luiz Orlando.

20 Entre os anos de 1984 e 1988, o Conselho Nacional de Cinema (Concine) estabelece um sistema de curta-metragem com júris de averiguação de qualidade. A obrigatoriedade de exibição nas salas comerciais alavanca a chamada "Primavera do Curta", quando tal formato ganha maior aceitação do público e prêmios internacionais, puxados por llha das flores (1989), de Jorge Furtado. 
confrontou as teses do racismo científico na secular Faculdade de Medicina da Bahia (FMB), ali localizada.

O ímpeto de valorizar a veia africana se intensifica no bloco afro Olodum, quando nomes como Luiz Orlando integram o Conselho Consultivo com a exibição de películas como Rio, Zona Norte (1957), também de Santos, que traz Grande Otelo no papel de um compositor de sambas plagiados ou relegados, o que poderia ser uma lição para muitos da plateia em um período de nascedouro de um projeto de embranquecimento sintetizado no axé music.

Nas ruas de pedra de Salvador, Luiz também ingressa no rastafarianismo como um fundador da Legiăo Rastafari e no renascimento da capoeira de Angola, onde municiou com imagens dali as cenas de O pagador de promessas (1962), de Anselmo Duarte, Barravento (1962), de Glauber Rocha, Vadiação (1954), de Alexandre Robatto Filho, ${ }^{21}$ e de qualquer lugar do Atlântico, em um repertório destacado pelo amigo Cobra Mansa, ou Cobrinha:

E aí Luiz Orlando trazia filmes da África, panafricanismo e aquela identidade que a gente tava buscando. Muitas vezes, ele conseguiu filmes norte-americanos com legenda, filmes de Angola, cada detalhe que a gente via: "Pô, parece, tá vendo aquela luta lá, aquela dança lá!”. Não quero dizer que aquelas identificações sejam corretas, mas naquele momento servia de ponto de afirmação. (Cinézio Feliciano Santana, informação verbal, 2019)

Nos arredores do Pelourinho se encontra o Palácio Tomé de Souza, sede da prefeitura. Nas eleições de 1988, em que Gilberto Gil era tido como forte pré-candidato, houve um aumento de candidatos negros à Câmera, a maioria homens de bairros com forte identificação étnico-racial (OLIVEIRA, 1991). Isto é um sinal de que a onda negra se ramifica e encontra um horizonte de possibilidades de integrar, na linha de frente, a repactuação das elites políticas da

21 Outros documentários: Capoeira Angola (1952), de Maynard, Dança de guerra (1968), de Moura, Gato/Capoeira (1979), de Cravo Neto, e Mestre Pastinha - Capoeira Angola (1982), de Vieira. 
redemocratização. As imagens vindas da África com que os cineclubistas cruzam têm a guerra como saída, a exemplo do catálogo em 16mm da XV Jornada, de 1986, que destacava obras vindas de Moçambique, ${ }^{22}$ São Tomé e Príncipe ${ }^{23}$ e Angola, ${ }^{24}$ e a persistência do apartheid, quando a XVII Jornada, de $1988,{ }^{25}$ homenageia Nelson Mandela.

As imagens da África do Sul - um país de maioria populacional negra, mas dominada por uma minoria branca - ecoam em territórios onde a ideia de segregação faz algum sentido, como é o caso dos moradores de outro polo cineclubista: Liberdade e São Caetano. Os dois nomes representam mais de uma dezena de bairros e comunidades marcados pela luta por moradia, haja vista o Largo Sussunga, onde Luiz Alberto, operário do polo petroquímico e um dos membros do cineclube, reimagina a luta sindical em Baía de Todos-osSantos e iria perceber que negros e brancos se diferenciam quando o assunto é repressão do Estado ao assistir Eles não usam Black-tie (1981), de Leon Hirszman, e ver o assassinato do personagem de Milton Gonçalves.

A coesão nas sessões envolvia crianças e, junto com elas, mulheres. Nomes como Romelita, Joselita Reis, Maria do Carmo, Valdicélia, Maria Ângela, Rosenilda, Valnésia, Rita de Cássia, Jussara e Déa estão entre as representantes dos cineclubes na FBC. São delas que vem a demanda por documentários sobre o trabalho doméstico, como em Vida de doméstica (1976), de Eliane Bandeira, e violência

22 Minha mãe África, de Bengt Lilienrooth, Killing a Dream e Pintores moçambicanos, de Rodrigo Gonçalves, Karingana, de Mário Borgneth, Água em Mueda, de Labi Mendonça e Teatro Popular de Moçambique e O comboio da vida, de Ismael Vuvo.

23 Caminho longe, primeiro filme do Instituto de Cinema Nacional, dirigido por Ismael Vuvo, moçambicano formado pelo instituto do seu país natal.

24 Testemunhas das vítimas de agressão da Unita, de Carlos Henrique. Filme da TV Popular de Angola, faz alusão aos ataques da União Nacional para a Independência Total de Angola (Unita), partido com apoio da África do Sul e dos EUA, contrário ao Movimento Popular de Angola (MPLA).

25 É exibido um filme sobre Mandela e sua esposa Winnie, não identificado, e outro, Fronteiras de sangue (1987), de Borgneth, uma coprodução Brasil e Moçambique. 
contra a mulher, como em Tribunal Bertha Lutz (1982), de João Batista de Andrade.

A metodologia de diálogo prezava por fazer perguntas para ler qualquer obra: o que gostou? O que sentiu? Gritou por quê? Assim, estereótipos são ressignificados, como nas personagens de Zezé Motta em Xica da Silva e a de Luiza Maranhão em A grande feira (1961), de Roberto Pires. Por sinal, no clássico baiano, as moradoras de Alagados reencontram parte da sua história quando o incêndio criminoso em 1964 destrói a feira de Água de Meninos e deixa muitas sem ter para onde ir, levando-as a erguer mais palafitas nos mangues. Ali, os jovens Déa e Raimundo caminham até assumir, nos anos 1990, o Espaço Cultural Alagados, aproveitando o sentimento dos filmes:

O Pagador de Promessas foi a coisa mais impressionante. Numa sala nos Alagados, ele na cruz, na hora foi o maior silêncio, quando Zé do Burro entrou na igreja, o pessoal deu dois passos na sala, como se tivesse acompanhando ele junto. Foi o negócio mais maluco que vi em minha vida. Doido mesmo. (Silva, informação verbal, 2004)

A léguas dali, no Engenho Velho da Federação, o ideal de comunidade vem dos terreiros, desde o secular Bogum até os que vão o rodeando, como a Casa Branca, Oxumarê, Cobre e outros mais recentes, como o Tanuri Junsara, da Makota Valdina. Ela e o ogã Jaime Sodré estavam à frente da associação de moradores e passaram a ter outra visão do que é ser um militante negro na criação do cineclube Grande Otelo:

Nunca esqueço que uma vez [Valdina] falando assim: - Esse pessoal dos militantes que fica na universidade... Andando pelo centro... Quero ver trabalhar na comunidade!? - Eu tô aqui, fazendo trabalho de cinema, mas sou militante negro. (Valdina de Oliveira Pinto, informação verbal, 2017) 
Pois bem, o nome do bairro da Makota remete à moenda de cana em um regime de exploração que rodeia o imaginário de Salvador. O documentário Açúcar negro (1987), de Michel Regnier, mostra a renovação dessa exploração aos haitianos. Já Rue cases negres (1983) vai além na direção da martinicana negra, Euzhan Palcy. Nos canaviais, a perpetuação do legado africano tem lastro nas mulheres e nos mais velhos, o que permite aos mais jovens a educação como horizonte de dias melhores.

Outra terra de terreiros é a região do Cabula. É lá que um cineclube funciona dentro da comunidade-escola Obá Biyi do Ilê Axé Opô Afonjá em São Gonçalo do Retiro. Além de assistir obras cinematográficas, essa comunidade idealizada por Mestre Didi busca participar na feitura dos filmes, como é o caso do pedagógico Orixá Ninú Ilé (Arte Sacra Negra 1) (1978), de Elbein, e Egungun (1982), de Brajsblat. No segundo, a câmera presencia rituais, eguns, conflitos internos e o funeral do sacerdote mais velho, até que as filmagens são encerradas e, dois anos depois, a obra concluída. O desafio era agora a permissão para exibir. Assim, a primeira exibição ocorre dentro da comunidade, na Ilha de Itaparica, sob condução do mestre projecionista Luiz Orlando. 


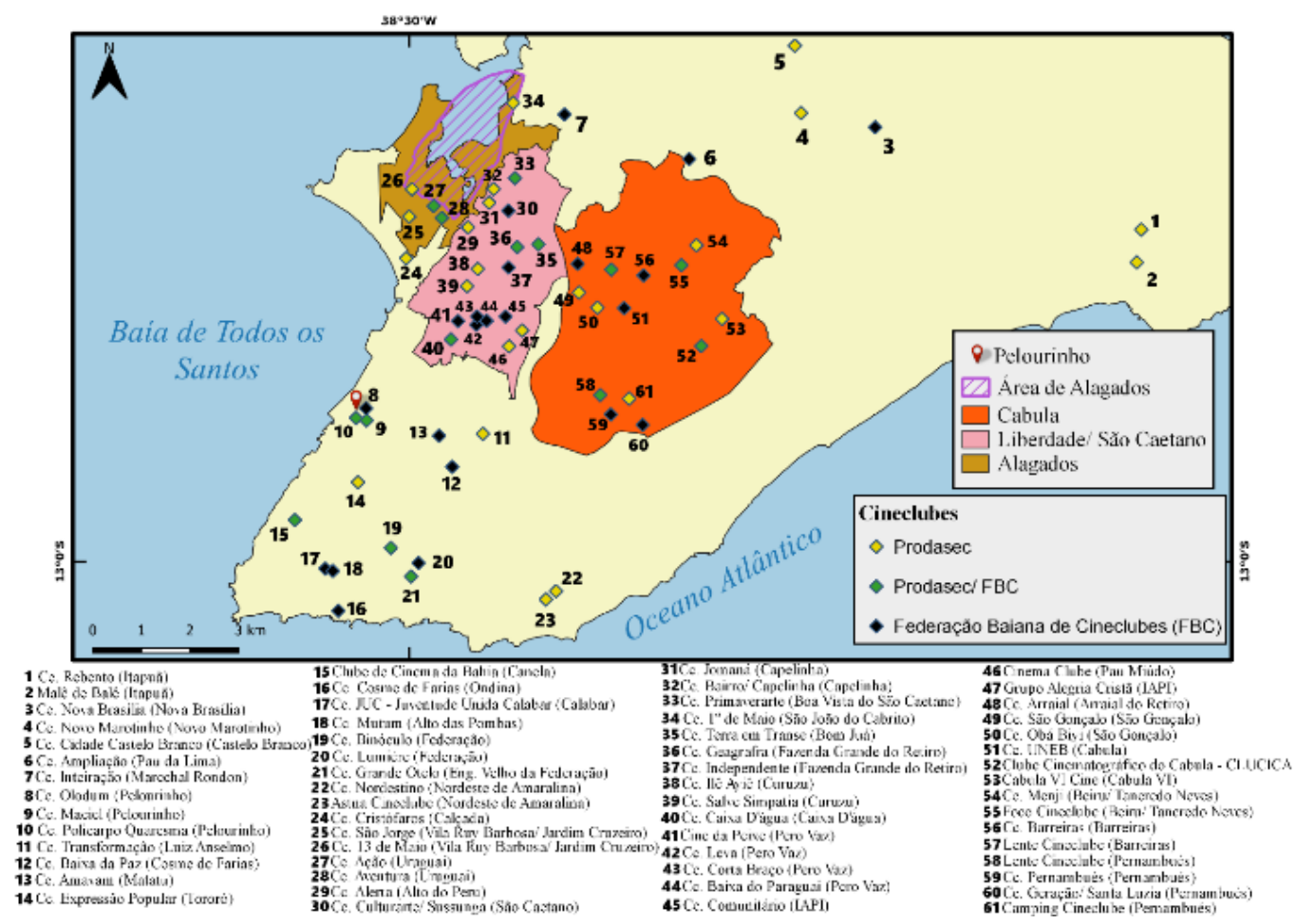

Fonte: Elaboração própria (2021)

\section{CONSIDERACÕES FINAIS}

Na cidade de Salvador, os terreiros de candomblé são o principal manancial de perpetuação do legado africano na formação de uma identidade subnacional, a baiana, e nacional, a brasileira, e, por conseguinte, nas relações dessa sociedade civil, de maioria populacional negra, com o Estado e suas políticas. É dessa instituição de criação e recriação na diáspora que se aprendeu o mero direito de existir, o da liberdade de ir e vir e de perpetuar seus cheiros, sons e imagens nas rodas e representações das indústrias culturais, além do objeto deste artigo: a negociação, influência e participação no Estado e suas políticas

A epistemologia dos terreiros está entranhada em uma geração de intelectuais, militantes e artistas que concebem um renascimento 
civilizatório calcado na igualdade da população que traz tal o histórico genocida nas marcas de seus corpos e nos seus modos de viver. O teor de denúncia ao mito da democracia racial nessa atuação é inerente e começa por construírem ou assumirem as suas próprias instituições, desde família, terreiros e grupos culturais até organizações políticas.A contribuição de Luiz Orlando é na direção de um cinema negro, feito por pessoas negras, e nesta passagem da história o desnudar do véu da raça tem como alvo uma formação de público embasada nas estratégias de troca e democratização das leituras filmicas. Ele é o curador, aquele que media a relação do público com as obras artísticas, e aponta para o cinema brasileiro, baiano e independente a constituição de uma linguagem que retroalimenta a cadeia produtiva com narrativas que dialogam com a vida do espectador, por vezes em formatos sintéticos e diretos, típicos do curta-metragem e do documentário.

Faz disso com a mandinga que driblou a subalternidade nas políticas e no mercado do cinema e audiovisual. E, para compreender tal jeito se faz necessário viver e conceber o cinema negro de Luiz por meio das ideias, textos, depoimentos e filmes que o acompanharam. Algo que não foi bem captado enquanto ele viveu, mas que aos poucos começa a ser desnudado a partir das memórias da comunidade negra, embora não se deva subestimar as hierarquias raciais locais e globais que se articulam com a economia e a política no cinema e audiovisual, a partir do controle das imagens e dos territórios, da distribuição e da exibição, o que inclui as instituições responsáveis por formar públicos, profissionais e pesquisas no setor.

\section{REFERÊNCIAS}

BACELAR, J. Mário Gusmão: um príncipe negro na terra dos dragões da maldade. Rio de Janeiro: Pallas, 2006.

BERNARDET, J.-C. O corpo da obra. Rio de Janeiro: Embrafilme, 1980.

BRASIL. Lei ${ }^{\circ}$ 7.505, de 2 de julho de 1986. Dispõe sobre os benefícios fiscais na área do imposto de renda concedidos a operações de caráter cultural ou artístico. Diário Oficial da União, Brasília, DF, 3 jun. 1986. 
CARIBÉ, P. A. Cinema de terreiro: o audiovisual negro de Luiz Orlando nos cineclubes em Salvador. 2019. Tese (Doutorado em Comunicação) Universidade de Brasília, Brasília, DF, 2019.

CARNEIRO, A. S. A construção do outro como não-ser como fundamento do ser. 2005. Tese (Doutorado em Educação) - Faculdade de Educação, Universidade de São Paulo, São Paulo, 2005.

CARVALHO, N. Cinema e representação racial: o cinema negro de Zózimo Bulbul. 2005. Tese (Doutorado em Sociologia) - Faculdade de Filosofia, Letras e Ciências Humanas, Universidade de São Paulo, São Paulo, 2005.

CINECLUBE sai da elite e vai até os bairros da periferia. Jornal da XI Jornada Brasileira de Curta-Metragem, Salvador, n. 6, p. 20-21, 1982.

DU BOIS, W. E. B. As almas da gente negra. Rio de Janeiro: Lacerda, 1999.

FUNDAÇÃO CULTURAL DO ESTADO DA BAHIA. Projeto de dinamização cultural nos bairros: síntese de uma experiência. Salvador: Funceb, 1985.

GILROY, P. O Atlântico negro: modernidade e dupla consciência. São Paulo: Editora 34, 2012.

JORNAL DA XV JORNADA BAIANA DE CINEMA. Salvador, n. 10. 1986.

MELO, I. F. C. Cinema, circuitos culturais e espaços formativos: novas sociabilidades e ambiência na Bahia (1968-1978). 2018. Tese (Doutorado em Ciências da Comunicação) - Escola de Comunicação e Artes, Universidade de São Paulo, São Paulo, 2018.

NASCIMENTO, J.; GAMA, H. (org.). Manuel R. Querino: seus artigos na revista do Instituto Histórico e Geográfico da Bahia. Salvador: Instituto Histórico e Geográfico da Bahia, 2009.

NEVES, D. O cinema de assunto e autor negros no Brasil. Cadernos Brasileiros: 80 Anos de Abolição, Rio de Janeiro, v. 10, n. 47, p. 75-81, 1968.

OCA. Evolução do número de salas de exibição: 1971 a 2019. Brasília, DF: Ancine, 2020. Disponível em: https://bit.ly/2WCKfGE. Acesso em: 20 ago. 2021.

OLIVEIRA, C. L. P. O Negro e o poder: os negros nas eleições de Salvador, em 1988. Cadernos do CRH, Salvador, 94-116, 1991.

SODRÉ, M. O terreiro e a cidade: a forma social negro-brasileira. Petrópolis: Vozes, 1988.

SOUZA, E. P. A ancestralidade africana de Mestre Didi: expandindo a intelectualidade negra brasileira. In: CONGRESSO INTERNACIONAL DA BRAZILIAN STUDIES ASSOCIATION, 9., 2008, Tulane. Anais [...]. Louisiana: Brasa, 2008. 